\title{
Hourglass-shaped resection technique for repair of tall mitral valve posterior leaflet prolapse
}

\author{
Masaru Sawazaki, MD, ${ }^{\mathrm{a}}$ Shiro Tomari, MD, ${ }^{\mathrm{a}}$ Naoto Izawa, $\mathrm{MD},{ }^{\mathrm{a}}$ and Yuichi Ueda, MD, $\mathrm{PhD}{ }^{\mathrm{b}}$
}

Objective: We developed a repair technique for an excessively high posterior leaflet of the mitral valve. This is an improvement of the folding plasty.

\begin{abstract}
Methods: The resection shape is that of an hourglass rather than a quadrangle. The vertical sides of the quadrangle curve inward, which helps to prevent the curtain effect or restriction that is common in the large triangular resection or folding plasty. We used hourglass resection for 26 tall posterior leaflets $(53.8 \%$ were Barlow disease) and triangular resection for 23 posterior leaflets of normal height (without Barlow disease).

Results: All surgeries were performed successfully. There was no mortality, no mitral regurgitation greater than moderate, and no systolic anterior motion of the anterior leaflet in the early postoperative period. One patient required a second pump run, and another required a second repair procedure. The mean follow-up period was 2.3 years (0.3-4.9 years) for the hourglass resection and 2.8 years (0.1-4.9 years) for the triangular resection. One patient in the triangular resection group died of rectal cancer. One patient treated with the hourglass resection via minithoracotomy required re-repair 1 month postoperatively due to suture dehiscence. For the hourglass and triangular resection groups, the most recent postoperative echocardiogram revealed no mitral regurgitation in 18 and 20 cases, respectively; mild mitral regurgitation in 7 and 3 cases, respectively; and moderate mitral regurgitation in 1 and 0 cases, respectively.
\end{abstract}

Conclusions: The short-term results of our strategy for posterior leaflet repair appear promising. (J Thorac Cardiovasc Surg 2013;146:275-7)

Conventional repair of posterior mitral valve prolapse involves quadrangular resection and annular plication. When the posterior leaflet is excessively tall, there is a risk of systolic anterior motion of the anterior leaflet (SAM), and a sliding plasty is used to prevent this. Combination of these methods requires annular plication, however, because the leaflet is resected quadrangularly, sacrificing a large amount of useful leaflet tissue. Additionally, we had 2 cases of mitral valve plasty with quadrangular resection that were complicated by mitral stenosis 5 years postoperatively and 1 case of stenosis that developed 9 years after sliding plasty, necessitating further surgery. The mitral stenosis was due to pannus formation, which is preventable with a larger postrepair mitral annular diameter. We therefore modified the folding plasty method by using a triangular or hourglass resection without annular plication at the resection site.

\footnotetext{
From the Department of Cardiovascular Surgery, ${ }^{a}$ Heart Valve Center, Komaki City Hospital, Komaki-city, Aichi, Japan; and Department of Cardiothoracic Surgery, ${ }^{\text {b }}$ Nagoya University Graduate School of Medicine, Nagoya, Aichi, Japan.

Disclosures: Authors have nothing to disclose with regard to commercial support.

Presented at The American Association for Thoracic Surgery Mitral Conclave,

New York, New York, May 5-6, 2011

Received for publication March 17, 2012; revisions received June 7, 2012; accepted for publication June 18, 2012; available ahead of print Dec 14, 2012.

Address for reprints: Masaru Sawazaki, MD, Komaki City Hospital, Cardiovascular Surgery, 1-20, Jyobushi, Komaki, Aichi 485-8520, Japan (E-mail: sawamasa7007bb@m7.gyao.ne.jp).

0022-5223/\$36.00

Crown Copyright (C) 2013 Published by Elsevier Inc. on behalf of The American Association for Thoracic Surgery

http://dx.doi.org/10.1016/j.jtcvs.2012.06.054
}

\section{MATERIALS AND METHODS}

Our goal was to create an ideally shaped leaflet without annular plication. The operative technique is selected on the basis of the height of the prolapsed leaflet. When the leaflet is not very tall, we use triangular resection. For an excessively tall leaflet $(\geq 1.8 \mathrm{~cm})$, we developed hourglass resection to prevent SAM. The hourglass shape consists of 2 triangles: the upper inverted triangle is resected and sutured to repair the prolapse of the rough zone, and the lower triangle is resected and sutured to the annulus to reduce the height of the leaflet and avoid the risk of SAM. When the resection area is narrow, the hourglass is composed of two triangles opposing each other. When the resection area is wider, the waist of the hourglass resection is made wider (Figure 1). From June 2007 to March 2012, a total of 65 patients with mitral regurgitation with Carpentier type II leaflet prolapse were surgically treated. Among them, 49 patients had a prolapsed posterior leaflet. Of these, 26 patients were treated by hourglass resection and 23 by triangular resection. The mean ages were $59.4 \pm 10.4$ years in the hourglass resection group and $64.2 \pm 12.4$ years in the triangular resection group. Barlow disease or forme fruste was present in $53.8 \%$ of the hourglass resection group and in $0 \%$ in the triangular resection group $(P<.001)$. For the hourglass resection and triangular resection groups, the left ventricular end diastolic diameters were $57.4 \pm 6.7 \mathrm{~mm}$ and $53.5 \pm 6.1 \mathrm{~mm}$, respectively; the left ventricular end systolic diameters were $34.6 \pm 4.6 \mathrm{~mm}$ and $34.7 \pm 7.0$ $\mathrm{mm}$, respectively; and the left ventricular ejection fractions were $69.5 \% \pm 6.9 \%$ and $63.8 \% \pm 11.4 \%$, respectively. Multiple leaflet prolapses were treated individually. Four patients were treated with both hourglass resection and triangular resection, and they were included in the hourglass resection group. One patient required 2 triangular resections. Three patients required 2 hourglass resections. Additional chordal replacements were used for 7 patients in the hourglass resection group and 3 in the triangular resection group, because the posterior leaflets of these patients had wide lesions that could not be repaired by resection alone. In such cases, we repaired the leaflets with a combination of chordal replacement and resection to adjust the remaining prolapse. 


\section{Abbreviation and Acronym \\ $\mathrm{SAM}=$ systolic anterior motion of the anterior leaflet}

Triangular resection of the anterior leaflet was used for three cases in which Barlow disease was present. Eleven patients underwent a right minithoracotomy.

Our concept involves making an ideally shaped leaflet from posterior leaflets of various sizes by using 2 resection techniques (triangular resection and hourglass resection) without annular plication. Mitral annuloplasty was performed with partial bands. In the hourglass resection and triangular resection groups, respectively concomitant procedures included the Cox maze procedure in 9 and 5 patients, tricuspid annuloplasty in 3 and 8 patients, coronary artery bypass grafting in 0 and 2 patients, the Bentall procedure in 0 patients and 1 patient, and aortic valve replacement in 0 patients and 1 patient.

\section{Follow-up}

The follow-up rate was $100 \%$, with all patients undergoing echocardiography at our institution at 1 and 3 months and yearly thereafter. The degree of mitral regurgitation was estimated from the regurgitant color Doppler area in the apical and long-axis views. The severity of mitral regurgitation was classed as none, mild, moderate, or severe by the echocardiographers and cardiologists.

\section{Statistical Analysis}

Comparisons between the groups were made with the Pearson $\chi^{2}$ test for categoric variables and the unpaired $t$ test for continuous variables. Statistical analyses were performed with JMP software (SAS Institute Inc, Cary, NC).

\section{RESULTS}

All lesions in both groups were repaired successfully with these techniques. There were no deaths, no mitral regurgitation greater than moderate, no SAM, and no hemolysis in the early postoperative period. One patient in the hourglass resection group required a second pump run, and the leaflet in that case required a second triangular resection procedure. One patient in the hourglass resection group who had undergone a minithoracotomy required a second procedure 1 month later as a result of suture dehiscence. The mean follow-up periods were $2.3 \pm 1.4$ years (0.3-4.9 years) and $2.8 \pm 1.6$ years (0.1-4.9 years) in the hourglass resection and triangular resection groups, respectively. The most recent postoperative echocardiogram in the hourglass resection and triangular resection groups revealed, respectively, no mitral regurgitation in 18 and 20 cases, mild mitral regurgitation in 7 and 3 cases, and moderate mitral regurgitation in 1 case and 0 cases.

\section{DISCUSSION}

Quadrangular resection or sliding plasty followed by annular plication provides good results in terms of survival and freedom from re-operation. ${ }^{1}$ These methods can prevent restricted leaflet motion or the curtain effect of the repaired leaflet, which can occur in large triangular resection. ${ }^{2}$ The reason for resecting the leaflet as a quadrangular shape, however, is unclear. In addition, annular plication at the repair site results in a relatively smaller mitral valve orifice. Another concern with quadrangular resection is that a large amount of leaflet tissue is sacrificed. Our strategy was to adopt triangular resection ${ }^{3}$ for a posterior leaflet of normal height and an hourglass resection for an excessively high posterior leaflet, without annular plication. For an excessively high posterior leaflet, sliding plasty ${ }^{4}$ is usually selected to prevent SAM. The incidence of SAM is reported as $9.8 \%$, and $8.3 \%$ of these require a second operation within 48 hours. ${ }^{5}$ The shortcomings of the sliding plasty are that it is a complicated procedure that involves a large annular plication. Folding plasty $^{6,7}$ is another option for a tall posterior leaflet, and it does not require annular plication. It does, however, place unnatural tension on the leaflets by folding the straight lines of the quadrangle. The coaptation depth between posterior scallops thus can become superficial, leading to the curtain effect. Moreover, additional procedures are sometimes required to correct the residual mitral regurgitation that results. The question remains as to why surgeons resect the prolapsed leaflet as a quadrangular shape when the folding plasty resects as much leaflet tissue as quadrangular resection or the sliding plasty. We therefore resected an excessively tall leaflet in the shape of an hourglass. The upper inverted triangle was sutured as in triangular resection, and the lower triangle was sutured with the annulus, as in the folding plasty. The result was a new, normal-sized, deeply coapted posterior scallop made from the autologous leaflet tissue that is usually resected during quadrangular resection and in folding plasty. The hourglass resection technique resects the smallest amount of tissue while forming a new ideally shaped posterior scallop that relieves tension on the posterior leaflet. Hourglass resection is therefore an improved version of the folding plasty. Although the same effect could be achieved by other techniques, such as triangular resection with height reduction of the leaflet, hourglass resection is a simple and reproducible technique.

In terms of limitations, it is notable that 1 patient treated by hourglass resection in this study required a second pump run because of residual leaflet prolapse. In this case, we added triangular resection. The cause of the remaining prolapse was an excessively small resection area, especially in the upper triangle of the hourglass shape. Determining the proper width for the leaflet resection is sometimes as difficult in hourglass resection as in the triangular resection or quadrangular resection. Another patient, who was initially treated by hourglass resection though a minithoracotomy, underwent standard sternotomy as a second treatment. The cause of recurrent mitral regurgitation was dehiscence of the suture in the upper triangle. More than $50 \%$ of the 


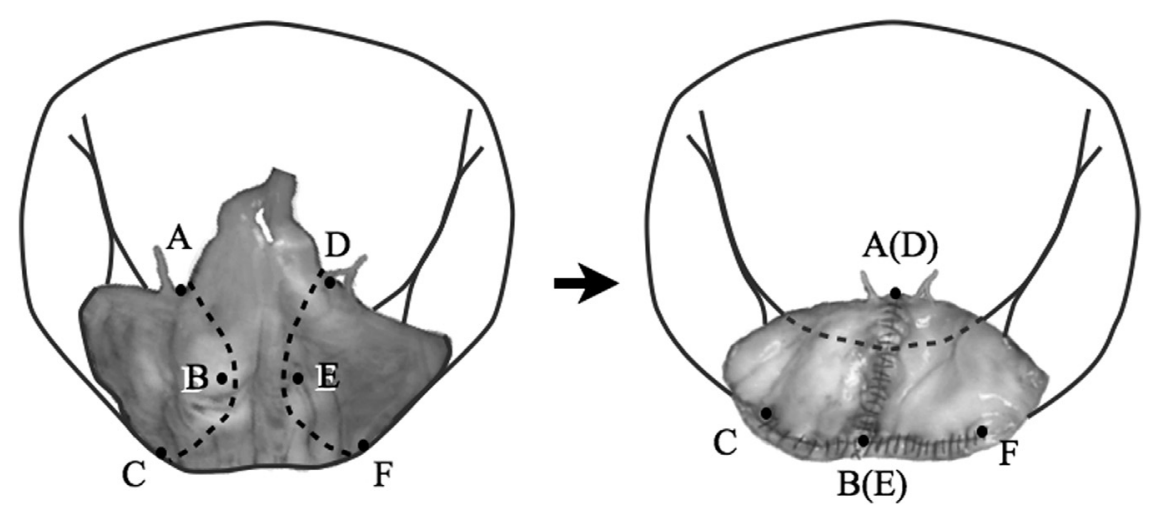

FIGURE 1. The vertical lines of the quadrangular resection curve inside. The cut edges $(A B$ and $D E)$ of the upper inverted triangle are sutured together. The cut edges ( $B C$ and $E F$ ) of the lower triangle are sutured to the annulus $(C F)$. AB $(\mathrm{DE})$ is the vertical height of the newly reconstructed leaflet $(1.5 \mathrm{~cm}$ ). The length of the waist of the hourglass $(B E)$ is calculated with the formula $\mathrm{BC}+\mathrm{EF}=\mathrm{CF}$. The cut edges $(B C$ and $E F)$ of the lower triangle should be in a convex shape to prevent restriction or the curtain effect.

patients in the hourglass resection group had Barlow disease or forme fruste, whereas all patients in the triangular resection group had fibroelastic deficiency. The durability and success rate of mitral valve plasty is not better, however, in Barlow disease than in fibroelastic deficiency. ${ }^{8}$ A similar technique was reported as a butterfly resection. ${ }^{9}$ For the narrow and tall posterior leaflet, the width of the hourglass is narrow, and the shape of the hourglass resection is close to a butterfly resection. For a wide lesion, however, the waist of the hourglass is wide, and the shape of the hourglass resection is different from that of the butterfly resection. In the case of an excessively wide posterior leaflet, even when the range of the butterfly resection is wide, it is difficult to remove sufficient leaflet tissue, and the sides of the upper triangle, which determines the height of the new leaflet, are too long. For wide lesions, we must adjust the resection shape to that of a wide hourglass. Some groups select chordal replacement not only for the anterior leaflet but also for the posterior leaflet. ${ }^{10}$ This technique does not require annular plication, but the redundant leaflet is still large after the repair. Consequently, in patients with a tall posterior leaflet, there is a risk for SAM.

\section{CONCLUSIONS}

The short-term results of our strategy for posterior leaflet repair were good. Our new concept of forming the ideal shape of the posterior leaflet may be useful. The triangular resection and the hourglass resection both had the benefits of preservation of sufficient leaflet tissue and avoidance of unnecessary annular plication. Nevertheless, the superior efficacy of hourglass resection relative quadrangular resection or sliding plasty could not be proved. Although hourglass resection is simpler than sliding plasty, we must await the results of future follow-up studies to confirm its long-term durability.

\section{References}

1. Carpentier A. Cardiac valve surgery - the "French correction." J Thorac Cardiovasc Surg. 1983;86:323-37.

2. Carpentier A, Adams DH, Filsoufi F. Techniques in type II posterior leaflet prolapse. In: Carpentier A, Adams DH, Filsoufi F, eds. Carpentier's reconstructive valve surgery: from valve analysis to valve reconstruction. Philadelphia: Saunders; 2010:117.

3. McGoon DC. Repair of mitral insufficiency due to ruptured chordae tendineae. J Thorac Cardiovasc Surg. 1960;39:357-62.

4. Perier P, Clausnizer B, Mistarz K. Carpentier "sliding leaflet" technique for re pair of the mitral valve: early results. Ann Thorac Surg. 1994;57:383-6.

5. Crescenzi G, Landoni G, Zangrillo A, Guarracino F, Rosica C, La Canna G, et al Management and decision-making strategy for systolic anterior motion after mitral valve repair. J Thorac Cardiovasc Surg. 2009;137:320-5.

6. Grossi EA, Galloway AC, Kallenbach K, Miller JS, Esposito R, Schwartz DS, et al. Early results of posterior leaflet folding plasty for mitral valve reconstruction. Ann Thorac Surg. 1998;65:1057-9.

7. Schwartz CF, Grossi EA, Ribakove GH, Ursomanno P, Mirabella M, Crooke GA, et al. Ten-year results of folding plasty in mitral valve repair. Ann Thorac Surg. 2010;89:488-9.

8. Flameng W, Meuris B, Herijers P, Herregods MC. Durability of mitral valve repair in Barlow disease versus fibroelastic deficiency. J Thorac Cardiovasc Surg. 2008; 135:274-82.

9. Asai T, Kinoshita T, Nishimura O, Kambara A, Suzuki T, Matsubayashi K. A novel design of posterior leaflet butterfly resection for mitral valve repair. Innovations (Phila). 2011;6:54-6.

10. Perier P, Hohenberger W, Lakew F, Batz G, Urbanski P, Zacher M, et al. Toward a new paradigm for the reconstruction of posterior leaflet prolapse: midterm results of the "respect rather than resect" approach. Ann Thorac Surg. 2008;86: 718-25. 